\title{
Study of Serum Cholesterol Level in Adult Obese Population of Karachi, Pakistan
}

\author{
Rubina Mushtaq, Rehana Mushtaq, Ambreen Akram, Sobia Khwaja, Shabbir Ahmed \\ Department of Zoology, Federal Urdu University of Arts Science and Technology, Karachi, Pakistan \\ Email: ambadn@hotmail.com, mushtaqrehana@ymail.com
}

Received 6 September 2014; revised 8 October 2014; accepted 25 October 2014

Copyright $@ 2014$ by authors and Scientific Research Publishing Inc.

This work is licensed under the Creative Commons Attribution International License (CC BY). http://creativecommons.org/licenses/by/4.0/

(c) $\underset{\mathrm{EY}}{\mathrm{EY}}$ Open Access

\section{Abstract}

Background: The present study was planned to investigate the level of cholesterol in obese/nonobese (normal) individuals according to their body mass index (BMI) and age in different population residing in Karachi. Aim: Comparison of serum cholesterol values of obese with normal subjects and comparison of BMI of obese and normal individuals. Methods: Selection of obese subjects was according to the WHO (1998) criteria. A total of 40 subjects 18 - 55 years of age participated in the study, among which 30 subjects (Mean Age $=29.47 \pm 1.99$ ) were obese (Mean $\mathrm{BMI}=35.41 \pm 0.878$ ) and 10 were controls with Mean age $=21.00 \pm 0.547$ and $\mathrm{BMI}=19.96 \pm 0.432$. An overnight fasting blood sample was obtained and serum total Cholesterol (T-CH) level was estimated. Results: Obese persons having Mean T-CH $=202.6 \pm 14.3$ and controls having Mean $\mathrm{T}-\mathrm{CH}=173.3 \pm 14.0$. The data were further divided into males and females. Obese females were 11 with their BMI $31.836 \pm 0.21$, mean age ranged at $28.73 \pm 4.04$ and T-CH 191.8 \pm 21.8 , while that of control females were 6 in number with their BMI ranged at $19.183 \pm 0.507$, age $21.000 \pm 0.894$ and Cholester $148.7 \pm 16.0$ in controls. Total numbers of obese males were 19 with their BMI ranged at $37.49 \pm 1.14$, age ranged at $29.89 \pm 2.19$ and cholesterol level ranged at $208.89 \pm 19.1$. Control males were 4 in number with their BMI ranged at $21.125 \pm 0.075$, age $21.250 \pm 0.479$ and their T-CH 128.7 \pm 8.72. Conclusion: The results of current study have reflected that BMI and total cholesterol concentration are higher in obese subjects.

\section{Keywords}

BMI, Obesity, Serum Cholesterol Levels

\section{Introduction}

Obesity is right now considered a pandemic, expanding quickly in many developed countries throughout the world. The incidence of being overweight and obese among United State grown-ups has expanded by $45 \%$ in 
the course of recent decades, from $44.8 \%$ in 1962 to $65.2 \%$ in 2002 [1]. Obesity is usually characterized as the presence of excessive body fat, yet the instance of fat distribution is critical regarding Diabetes mellitus (DM) hazard and many other metabolic abnormalities included in the metabolic syndrome. Men are more prone to have abdominal or upper-body obesity called android obesity, initially depicted by Vague in 1956 [2], though females are more inclined to have a gluteofemoral or lower-body pattern of fat dissemination (gynoid obesity). Obesity has been defined as a weight more than $20 \%$ above what is considered normal according to standard age, height, and weight tables, or by a complex formula known as the body mass index [3]. Overweight and obesity keep on increasing considerably around the world, influencing all ages, genders and races [4]. Pakistan National Representative Survey demonstrated 25\% of the populations to be overweight as indicated by the Asian-particular BMI cutoff values and 10.3\% are obese. This information confirms a major health issue in Pakistan [5]. Obese individuals with body mass index (BMI) greater than $30 \mathrm{~kg} / \mathrm{m}^{2}$ have a more serious danger of dying earlier than the non-obese [6]. Because of excess amount of body fat ratio in obesity, BMI, waist circumference (WC) and waist-to-hip ratio (WHR) have been utilized as basic anthropometric indices (AI) for evaluating the sum and appropriation of muscle to fat ratio ratios [7] and are useful indices in foreseeing the risk of type 2 diabetes, hypertension, and cardiovascular diseases (CVDs) in grown-ups [8]. Generally among the over three indices, BMI has been demonstrated to be the most helpful and useful one in characterizing obesity in people. Obesity and abdominal obesity specifically, is definitely connected with an unfavorable dyslipidemic profile and an expanded danger for coronary vein artery disease [9]. Saturated fats and cholesterol in the diet play an important role in the etiology of hypercholesterolemia and act as a danger element for CHD [10]. Grundy in 1987 reported that the high level of plasma cholesterol is because of an increased in the level of low-density lipoprotein cholesterol (LDL-C) [11]. Polyunsaturated fat diet decreases plasma cholesterol level and beta lipoprotein when substituted for saturated fats [12]. Saturated fats and cholesterol in the diet cause elevated serum cholesterol while diet low in saturated fat and cholesterol reduce cholesterol level in people [13]. Polyunsaturated unsaturated fats (PUFA) in diet lower triglyceride (TG), very low-density lipoprotein cholesterol (VLDL-C), low-density lipoprotein cholesterol (LDL-C), and furthermore high-density lipoprotein cholesterol (HDL-C) [14]. Tayyab et al., in 1991 watched that saturated fats raised the serum total cholesterol (TC), mono unsaturated fatty acids (MUFA) expanded HDL-C and PUFA diminished both TC and HDL-C. Lifted LDL-C and diminished HDL-C in plasma have been separately recognized to be connected with expanded danger for CHD in men [15].

The vital basic constituent in the cell layer of numerous vertebrates is cholesterol [16].

$\mathrm{BMI}$ is calculated by the following formula:

$$
\operatorname{BMI}\left(\mathrm{kg} / \mathrm{m}^{2}\right)=\text { Weight } / \text { Height }^{2}
$$

An attractive BMI as indicated by the WHO (1998), prescribed cut-offs for Asians is considered to be between 18.5 and $22.9 \mathrm{~kg} / \mathrm{m}^{2}$. A BMI of $23-24.9 \mathrm{~kg} / \mathrm{m}^{2}$ is defined as "overweight" and BMI $>25 \mathrm{~kg} / \mathrm{m}^{2}$ as "obese" [17]-[18].

Other than all the preventive measures that are screening for indices of obesity and dyslipidemia, the prevalence of the obesity and its inconveniences is expanding worldwide and is one of the major public health issues. The reason for this study was to focus on the relationship of lipid profile in obese versus non-obese patients and to focus on the frequency of dyslipidemia in these two gatherings.

\section{Materials and Methods}

The present study was conducted at Federal Urdu University of Arts, Science and Technology (FUUAST) Gulshan e Iqbal Campus Karachi; all volunteers were students, and faculty members of the university.

Total of 40 subjects including 30 obese male and females and 10 controls (non-obese) male and female with aged 18 - 50 were randomly selected for the study. All subjects were from different socio-economic groups. To remove bias, subjects with known hypertension, diabetes, alcoholics etc. were excluded from the study. The duration of the study was seven months. A written informed consent was obtained from each subject and the procedure pertaining to study was explained to each subject. All procedures for the study were approved by the ethical committee of University. A desirable BMI according to the WHO (1998) [19] recommended cut-offs for Asians is considered to be between 18.5 and $22.9 \mathrm{~kg} / \mathrm{m}^{2}$. A BMI of $23-24.9 \mathrm{~kg} / \mathrm{m}^{2}$ is defined as "overweight" and BMI $>25 \mathrm{~kg} / \mathrm{m}^{2}$ as "obese" [20]. 
Serum samples were collected after 12 hours of fasting. Cholesterol levels were determined by using commercially available kit (LINEAR CHEMICALS S.L. Joquim Costa $182^{\mathrm{a}}$ planta. Montgat, Barcelona, SPAIN website http://www.linear.es).

\section{Results}

The study has been focused to investigate the comparison of age; body mass index and total cholesterol, in obese and non-obese groups in the sera were pertinently assessed separately in both groups.

\subsection{Total Obese Versus Total Control}

\subsubsection{Age}

The Table 1 presents pattern of age in control and obese groups. The age of obese subjects ranged at $29.47 \pm$ 1.99 in subjects of both gender and $21.10 \pm 0.547$ in non-obese subjects of both gender. The results are statistically significant $(\mathrm{P}<0.001)$. The subjects were in close range and well suited for the comparisons.

\subsubsection{Body Mass Index (BMI)}

The Table 2 presents pattern of Body Mass Index (BMI) in control and obese groups. Body mass index averaged at $19.96 \pm 0.432 \mathrm{~kg} / \mathrm{m}^{2}$ and $35.41 \pm 0.878 \mathrm{~kg} / \mathrm{m}^{2}$ in the control and obese subjects respectively. Results are highly significant $(\mathrm{P}<0.001)$. Body mass index of control subjects was lower as compare to obese.

\subsubsection{Total Cholesterol ( $\mathrm{T}-\mathrm{CH})$}

The Table 3 presents pattern of total cholesterol in control and obese groups. A concentration of total cholesterol was $173.3 \pm 14.0 \mathrm{mg} / \mathrm{dl}$ in and $202.6 \pm 14.3 \mathrm{mg} / \mathrm{dl}$ in the control and obese subjects correspondingly (P > 0.05). An elevated level of cholesterol concentration was experienced in obese subjects, as compared to control. In summary from the above results of this fraction in both groups it is quite obvious that obesity may effect on cholesterol concentration.

\subsection{Obese Females versus Control Females}

The data of obese and non obese subjects were categories according to gender that is into males and female for further study.

Table 1. Age of obese and control persons.

\begin{tabular}{cccc}
\hline Age & Total Obese $(\mathrm{n}=30)$ & Total Control $(\mathrm{n}=10)$ & $\mathrm{P}$ Values \\
Mean & $29.47 \pm 1.99$ years & $21.10 \pm 0.547$ years & 0.54 \\
SE Mean & 1.99 & 21.00 \\
Median & 24.50 & 0.001 \\
\hline
\end{tabular}

Table 2. BMI of obese and control persons.

\begin{tabular}{cccc}
\hline BMI & Total Obese $(\mathrm{n}=30)$ & Total Control $(\mathrm{n}=10)$ & P Value \\
Mean & $35.41 \pm 0.878 \mathrm{~kg} / \mathrm{m}^{2}$ & $19.96 \pm 0.432 \mathrm{~kg} / \mathrm{m}^{2}$ & $\mathrm{P}<0.001$ \\
SE Mean & 0.87 & 0.43 & \\
Median & 33.40 & 20.65 & \\
\hline
\end{tabular}

Table 3. Cholesterol level of obese and control person.

\begin{tabular}{cccc}
\hline Cholesterol & Total Obese $(\mathrm{n}=30)$ & Total Control $(\mathrm{n}=10)$ & $\mathrm{P}$ Values \\
\hline Mean & $202.6 \pm 14.3 \mathrm{mg} / \mathrm{dl}$ & $173.3 \pm 14.0 \mathrm{mg} / \mathrm{dl}$ & 14.0 \\
SE Mean & 14.3 & 174.5 \\
Median & 187.0 & 0.05 \\
\hline
\end{tabular}


Table 4 presents the comparative analysis of obese and non obese females.

In this group total number of obese females were 11 and those of controls were 6 in number with their BMI ranged at $31.836 \pm 0.211$ (obese female) and $19.183 \pm 0.507$ in control/non-obese females. The results were statistically highly significant $(\mathrm{P}<0.001)$. In this group obese and control female were with their mean age ranged at $28.73 \pm 4.04$ and $21.000 \pm 0.894$ respectively. The values were not statistically significant $(\mathrm{P}>0.05)$. Similarly obese females with their cholesterol values were $191.8 \pm 21.8$ and $148.7 \pm 16.0$ in controls. The values were not statistically significant $(\mathrm{P}>0.05)$.

\subsection{Obese Males versus Control Males}

Table 5 presents the comparative analysis of age, BMI and total Cholesterol of obese and non-obese males. In this group total number of obese males were 19 and that of control males were 4 in number with their BMI ranged at $37.49 \pm 1.14$ (obese male) and BMI ranged at $21.125 \pm 0.075$ (control males). The values were statistically highly significant $(\mathrm{P}<0.001)$. In this group obese males with their age ranged at $29.89 \pm 2.19$ and control males with their age averaged at $21.250 \pm 0.479$. The values were statistically significant $(\mathrm{P}<0.01)$. Similarly obese males and control with their cholesterol level ranged at $208.89 \pm 19.1$ and $128.7 \pm 8.72$ respectively. The values were not statistically significant $(\mathrm{P}>0.05)$.

\section{Discussion}

Obesity increases the predominance of nearly every anomalous lipid profile. Being overweight seems as significant risk factor for chronic diseases, for example, arteriosclerosis, ischemic coronary illness and diabetes, all of which are significant reason for morbidity and mortality [9]. It is an important issue around the world, and its frequency is increasing in both developed and developing countries with changes in dietary habits and activity level [21]. Being overweight and obesity lead to genuine wellbeing results, with the danger expanding logically with body mass record (BMI) and hence danger of cardiovascular sickness, type 2 diabetes and a few diseases includes endometrial, breast and colon cancer [22].

Overweight and obesity prompts numerous complexities, including BMI, diabetes, dyslipidemia and hypertension. A large portion of the historic point considers on these cardiovascular danger components have been carried out on western population. It is normal that as the BMI builds, the recurrence of these complications will additionally build. In our study contrast between BMI groups (normal, obese) were discovered just for serum cholesterol level. These results are in accordance with the results of other studies, which demonstrated that obesity is steady parameters related dyslipidemia and cardiovascular hazard in most population [19] [20]. In our study mean cholesterol and BMI showed a positive correlation. These findings are in accordance with the results from other western studies [23]-[24].

A few studies on Asian population additionally demonstrated the same discoveries [25]. Our study correlation of mean cholesterol with BMI was strong. Mean age in our study was $29.47 \pm 1.99$ years, which is the best representative of adult population. Mean BMI in our study was in the obese range i.e. $35.41 \pm 0.878 \mathrm{Kg} / \mathrm{m}^{2}$. Hus-

Table 4. Age, BMI and cholesterol of obese and control females.

\begin{tabular}{rccc}
\hline Parameters & Obese Females $(\mathrm{n}=11)$ & Control Females $(\mathrm{n}=6)$ & $\mathrm{P}$ Values \\
\hline Age Mean & $28.73 \pm 4.04$ & $21.000 \pm 0.894$ & $\mathrm{P}>0.05$ \\
BMI Mean & $31.836 \pm 0.211$ & $19.183 \pm 0.507$ & $\mathrm{P}<0.001$ \\
Cholesterol Mean & $191.8 \pm 21.8$ & $128.7 \pm 8.72$ & $\mathrm{P}>0.05$ \\
\hline
\end{tabular}

Table 5. Age, BMI and cholesterol of obese and control males.

\begin{tabular}{cccc}
\hline Parameters & Obese Males $(\mathrm{n}=19)$ & Control Males $(\mathrm{n}=4)$ & $\mathrm{P}$ Values \\
\hline Age Mean & $29.89 \pm 2.19$ & $21.250 \pm 0.479$ & \\
BMI Mean & $37.49 \pm 1.14$ & $21.125 \pm 0.075$ & 0.01 \\
Cholesterol Mean & $208.89 \pm 19.1$ & $128.7 \pm 8.72$ & $\mathrm{P}<0.001$ \\
\hline
\end{tabular}


sain et al., 2009 reported a mean BMI of more than 28 in diabetics as well as in non-diabetics [26]. Different studies done in our neighboring nations additionally demonstrated high BMI and huge commonness of obesity [27].

In a region where most of the population has poor access to good nourishment sustenance, discovering BMI in the overweight reach is disturbing. It demonstrates that notwithstanding sustenance, obesity is connected with other variables like hereditary qualities and lack of activity. Our studies additionally demonstrated that the majority of the people were not performing any exercise. The relationship of BMI and cholesterol in our study is firm modification for age, gender and exercise have likewise demonstrated that in both men and ladies, BMI was connected with cardiovascular danger figures yet the affiliation was no longer significant after age alteration. Like western countries our population is likewise at danger of obesity. BMI ought to be routinely weighed in clinical practice and epidemiological reviews. Our people need formal direction about healthy life style particularly about diet and exercise [28].

Rapidly increasing obesity prevalence rates necessitate weight management to be a priority for the prevention and treatment of chronic diseases.

\section{Conclusion}

In the present, study we compared the BMI and total cholesterol of non-obese and obese population of Karachi. The results of current study have reflected that BMI and total cholesterol concentration are higher in obese subjects. The increasing trend of obesity in the developing country like Pakistan specifically in females because these are socially subjected to sedentary life pattern is concerning. Thus public health authorities are strongly suggested to focus on this issue seriously.

\section{References}

[1] Ruhm, C.J. (2007) Current and Future Prevalence of Obesity and Severe Obesity in the United States. National Bureau of Economic Research, Working Paper No. 13181.

[2] Vague, J. (1956) The Degree of Masculine Differentiation of Obesities: A Factor Determining Predisposition to Diabetes, Atherosclerosis, Gout, and Uric Calculous Disease. The American Journal of Clinical Nutrition, 4, 20-34.

[3] The American Heritage (2004) Dictionary of the English Language. 4th Edition, Turtleback, USA.

[4] Tanner (2005) The Scientific Definition of Obesity and Its Danger. Mercola Author: Total Health Program. http://www.mercola.com

[5] Jafar, T.H., Chaturvedi, N. and Papps, G. (2006) Prevalence of Overweight and Obesity and Their Association with Hypertension and Diabetes Mellitus in an Indo-Asian Population. CMAJ, 175, 1071-1017. http://dx.doi.org/10.1503/cmaj.060464

[6] Ashwell, M. (1994) Obesity in Men and Women. International Journal of Obesity and Related Metabolic Disorders, 18, 1-7.

[7] Pouliot, M.C., Despres, J.P., Lemieux, S., Moorjani, S., Bouchard, C., Tremblay, A., Nadeau, A. and Lupien, P.J. (1994) Waist Circumference and Abdominal Sagittal Diameter: Best Simple Anthropometric Indexes of Abdominal Visceral Adipose Tissue Accumulation and Related Cardiovascular Risk in Men and Women. American Journal of Cardiology, 73, 460-468. http://dx.doi.org/10.1016/0002-9149(94)90676-9

[8] Zhu, S., Wang, Z., Heshka, S., Heo, M., Faith, M.S. and Heymsfield, S.B. (2002) Waist Circumference and ObesityAssociated Risk Factors among Whites in the Third National Health and Nutrition Examination Survey: Clinical Action Thresholds. The American Journal of Clinical Nutrition, 76, 743-749.

[9] Kissebah, A.H. and Krakower, G.R. (1994) Regional Adiposity and Morbidity. Physiological Reviews, 74, 761-811.

[10] National Institutes of Health \& National Heart, Lung, and Blood Institute (1998) Clinical Guidelines on the Identifi cation, Evaluation, and Treatment of Overweight and Obesity in Adults. The Evidence Report, NIH Publication No. 98-4083, US Department of Health and Human Services, Public Health Service, Bethesda, MD, p. 74.

[11] Grundy, S.M. (1987) Monounsaturated Fatty Acid, Plasma Cholesterol and Coronary Heart Disease. The American Journal of Clinical Nutrition, 45, 1168-1175.

[12] Vega, G.L., Groszek, E., Wofl, R. and Grundy, S.M. (1982) Influence of Polyunsaturated Fats on Composition of Plasma Lipoproteins and Apoliproteins. Journal of Lipid Research, 23, 811-822.

[13] Schaefer, E.J., Levy, R.I., Ernst, R.D., Sant, F.D.V. and Brewer, H.B. (1981) The Effect of Low Cholesterol, High Polyunsaturated Fat and Low Fat Diet on Plasma Lipid and Lipoprotein Cholesterol Levels in Normal and Hyperchole- 
stremic Subjects. The American Journal of Clinical Nutrition, 34, 1758-1763.

[14] Shepherd, J., Packard, C.V., Grundy, S.M., Yeshurun, D., Gotto Jr., A.M. and Taunton, O.D. (1980) Effects of Saturated and Polyunsaturated Fat Diets on the Chemical Composition and Metabolism of Low Density Lipoproteins in Men. Journal of Lipid Research, 21, 91-99.

[15] Tayyab, M., Shad, M.A., Khan, H. and Choudhry, N.A. (1991) Effects of Dietry Lipids on Serum Lipid Profile. Proceedings of Third International Conference. Pakistan Journal of Pathology, 109, 55-56.

[16] Ikonen, E. (2008) Cellular Cholesterol Trafficking and Compartmentalization. Nature Reviews Molecular Cell Biology, 9, 125-138. http://dx.doi.org/10.1038/nrm2336

[17] World Health Organization (1998) Obesity: Preventing and Managing the Global Epidemic. Report of a WHO Consultation on Obesity, World Health Organization, Geneva, 3-5 June 1998.

[18] Low, S., Chin, M.C., Ma, S., Heng, D. and Deurenberg-Yap, M. (2009) Rationale for Redefining Obesity in Asian. Annals Academy of Medicine Singapore, 38, 66-69.

[19] Panagiotakos, D.B., Pitsavos, C., Chrysohoou, C., Risvas, G., Kontogianni, M.D. and Zampelas, A. (2004) Epidemeology of Overweight and Obesity in a Greek Adult Population: The ATTICA Study. Obesity Research, 12, 1914-1920. http://dx.doi.org/10.1038/oby.2004.239

[20] Kragelund, C., Hassager, C., Hildebrandt, P., Torp-Pedersen, C. and Kober, L. (2005) Impact of Obesity on Long Term Prognosis Following Acute Myocardial Infarction. International Journal of Cardiology, 98, 123-131. http://dx.doi.org/10.1016/j.ijcard.2004.03.042

[21] Flegal, K.M., Graubard, B.I., Williamson, D.F. and Gail, M.H. (2005) Excess Deaths Associated with Underweight, Overweight, and Obesity. Journal of the American Medical Association, 293, 1861-1867.

[22] World Health Organization (2006) Global Strategies on Diet, Physical Activity and Health. http://www.who.int/dietphysicalactivity/publications/facts/obesity/en/

[23] Pucarin-Evetkovil, J., Mustajbegovic, J., Jelinic, J.D., Senta, A., Nola, I.A. and Ivwnkovic, D. (2006) Body Mass Index and Nutrition as Determinates of Health and Disease in Population of Croatian Adriatic Islands. Croatian Medical Journal, 47, 619-626.

[24] Costa, G.B., Horta, N., Resende, Z.F., Souza, G., Barreto, L.M. and Correia, L.H. (2009) Body Mass Index Has Good Correlation with Protherosclerotic Profile in Children and Adolescents. Arquivos Brasileiros de Cardiologia, 93, 261267. http://dx.doi.org/10.1590/S0066-782X2009000900010

[25] Aghasadeghi, K., Zarei-Nezhad, M., Keshavarzi, A. and Mehravanid, D. (2008) The Prevalence of Coronary Risk Factors in Iranian Lor Migrating Tribe. Archives of Iranian Medicine, 11, 322-325.

[26] Hussain, I., Sana, B., Waheed, K. and Qaisera, S. (2009) Association of Type 2 Diabetes Mellitus with Biometric Variable: A Study in Sir Ganga Ram Hospital, Lahore. Annals of King Edward Medical University, 15, 48-53.

[27] Azizi, F., Rahmani, M., Emami, H., Mimian, P., Hajipur, R. and Madjid, M. (2002) Cardiovascular Risk Factors in an Iranian Urban Population: Tehran Lipid and Glucose Study (Phase I). Sozial-und Praventivmedizin, 47, 408-426. http://dx.doi.org/10.1007/s000380200008

[28] Turcato, E., Bosello, O., Di Francesco, V., Harris, T.B., Zoico, E. and Bissow, L. (2000) Waist Circumference and Abdominal Sagittal Diameter as Surrogates of Body Fat Distribution in the Elderly Their Relation with Cardiovascular Risk Factors. International Journal of Obesity and Related Metabolic Disorders, 24, 1005-1010. http://dx.doi.org/10.1038/sj.ijo.0801352 
Scientific Research Publishing (SCIRP) is one of the largest Open Access journal publishers. It is currently publishing more than 200 open access, online, peer-reviewed journals covering a wide range of academic disciplines. SCIRP serves the worldwide academic communities and contributes to the progress and application of science with its publication.

Other selected journals from SCIRP are listed as below. Submit your manuscript to us via either submit@scirp.org or Online Submission Portal.
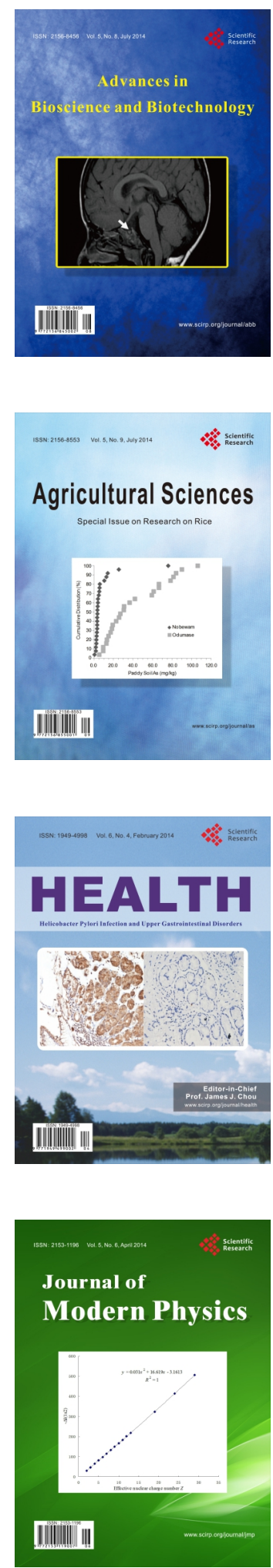
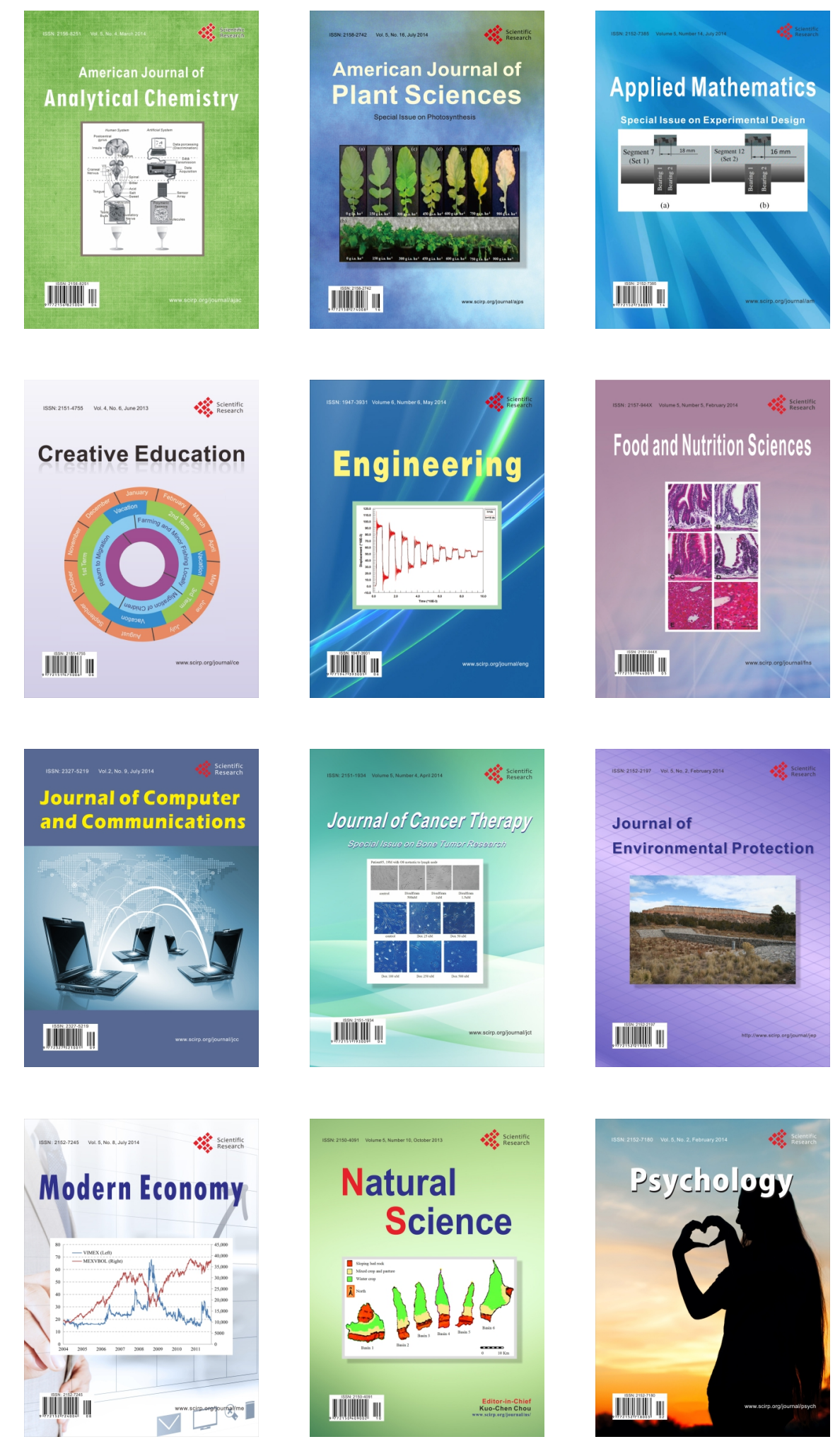